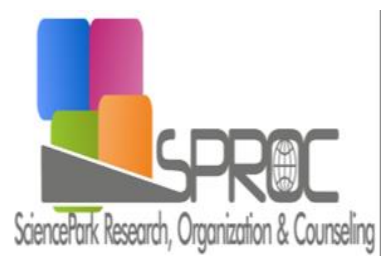

\title{
TELL and Innovated BB Study Materials Reflecting Learning Style Preferences
}

\section{Dagmar El-Hmoudova *}

Suggested Citation:

Trends and Issues Proceedings on Humanities and Social Sciences.

Abstract 
1. Introduction 


\section{Methods}

\section{intuitive}

\section{Sensitive}

Visual

reflexively verbal

$$
\text { Actively }
$$

Sequentially globally

Table 2. Felder Learning Styles Dimensions.

\section{Perception}

Entry channel

Processing

Understanding 
Sensitive Learning Style

Intuitive Learning Style:

Visual Learning Style:

Verbal Learning Style:

Active Learning Style:

Reflexive Learning Style 


\section{Sequential Learning Style}

\section{Global Learning Style:}

Table 3. Examples of How TELL can Support Language Learning Process

\begin{tabular}{ll}
\hline Type of learning activity & Examples of how TELL can support it \\
\hline Repetition and memorization & \\
Input - making it comprehensible & Including images to clarify meaning. \\
Salience and noticing & translations etc \\
Output & Writing blogs and e-mails. \\
Interaction & Watching YouTube videos.
\end{tabular}




\section{Methods and data collection}

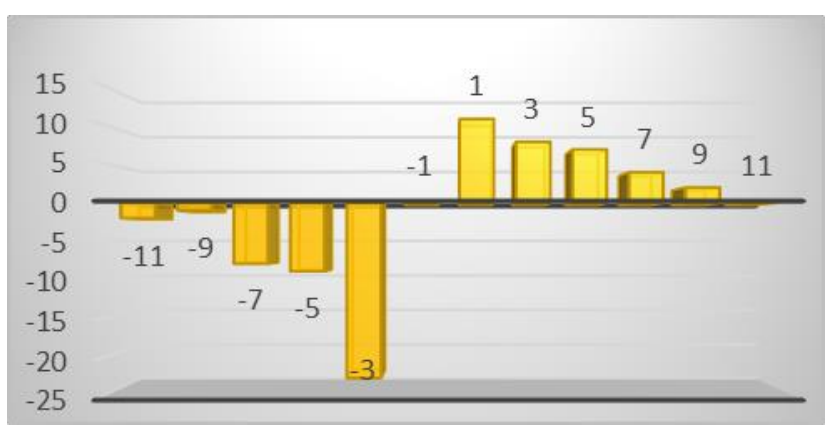

Figure 1. Active/reflexive preference in focus group

focus

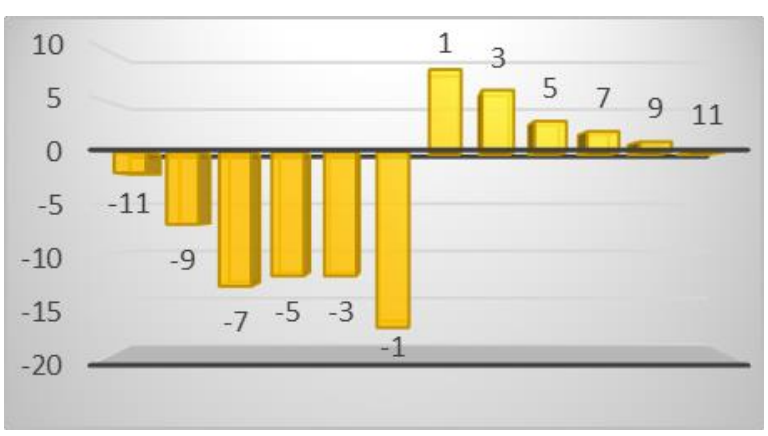

Figure 3. Sensing/intuitive preference in focus group

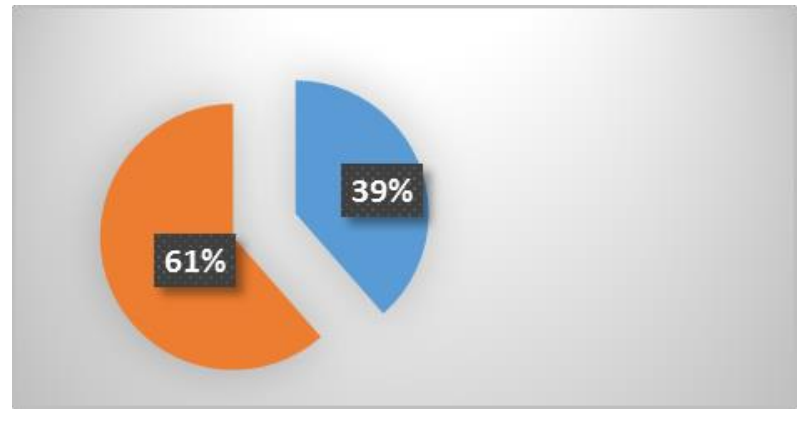

Figure 2. Active/reflexive preference in \%. preference in group

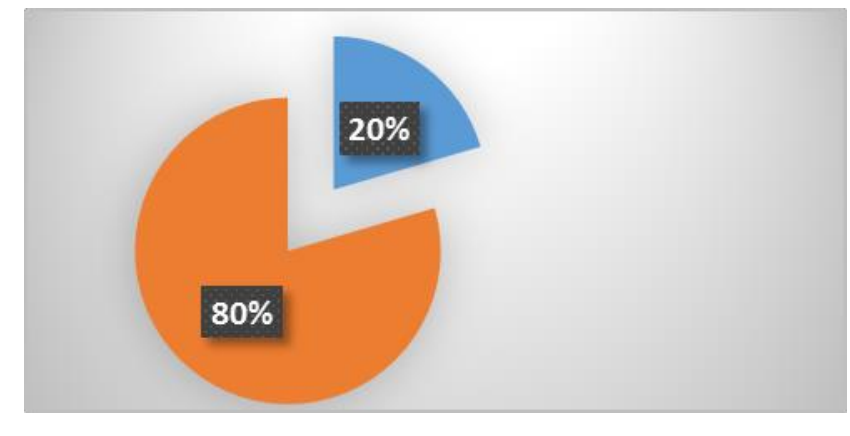

Figure 4. Sensing/intuitive preference in \% 


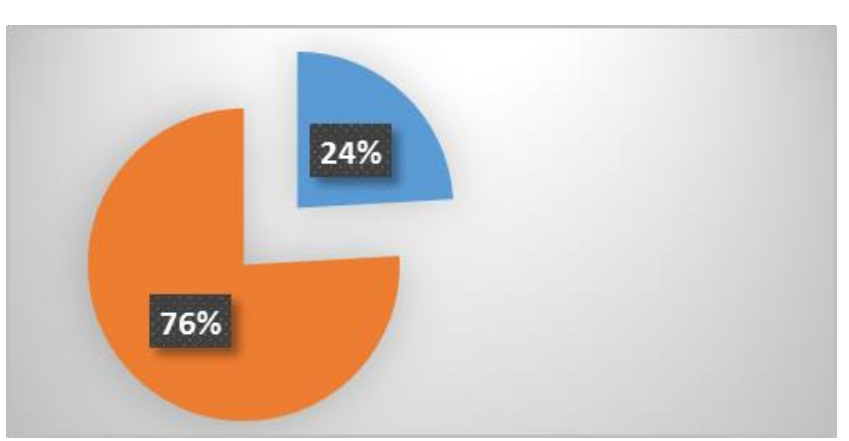

Figure 5. Visual/verbal preference in focus group

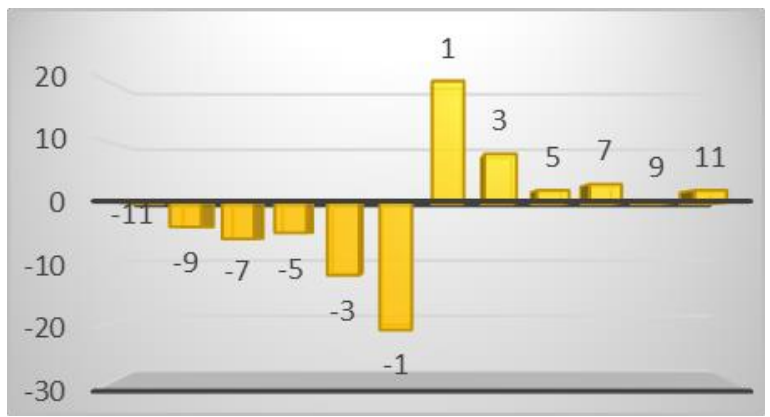

Figure 7. Sequential/global preference in focus group
Figure 6. Visual/verbal preference in \%.

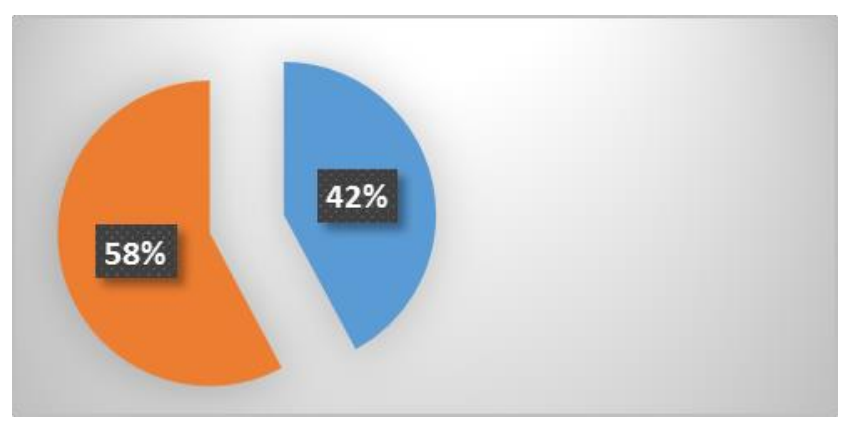

Figure 8. Sequential/global preference in $\%$. 


\section{Results and Implications}


Figure 9. Study Materials Preferences.

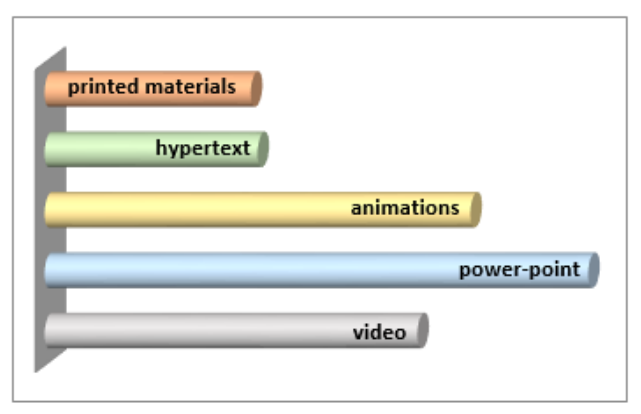

\section{Conclusion}

\section{Acknowledgements}

\section{References}

Learning Future: Education, technology and Social Change

Education, 78

International Journal on Engineering Education, 21

Educational Technology \& Society, 12

British Journal of Management, 7

How languages are learned 